
\title{
28 Research Suare \\ CD45dimCD34+CD38-CD133+ cells function as leukemic stem cells in acute myeloid leukemia
}

\section{Sook-Kyoung Heo}

University of Ulsan College of Medicine

\section{Eui-Kyu Noh}

Ulsan University Hospital

\section{Yoo Kyung Jeong}

University of Ulsan College of Medicine

Jaekyung Cheon

Ulsan University Hospital

\section{SuJin Koh}

University of Ulsan College of Medicine

\section{Young Joo Min}

University of Ulsan College of Medicine

\section{Yunsuk Choi}

University of Ulsan College of Medicine Jae-Cheol Jo ( $\sim$ jcjo97@hanmail.net)

Ulsan University Hospital, University of Ulsan College of Medicine https://orcid.org/0000-0001-60147977

\section{Research article}

Keywords: Acute myeloid leukemia, Leukemic stem cells, CD45dimCD34+CD38-CD133+cells, Prognosis, Immunophenotyping

Posted Date: October 12th, 2019

DOI: https://doi.org/10.21203/rs.2.15973/v1

License: (c) (1) This work is licensed under a Creative Commons Attribution 4.0 International License. Read Full License 


\section{Abstract}

Leukemia stem cells (LSCs) in acute myeloid leukemia (AML) played important roles in development of leukemia, chemotherapeutic drug resistance, and disease relapse and progression. The identification of LSCs and targeting therapies for them has been under investigation. We examined the CD45 dim CD34 + CD38 - CD133 + cells on bone marrow samples of hematologic malignancies and healthy controls using four-color flow cytometry experiments. Interestingly, the CD45 dim CD34 + CD38 - CD133 + cells were highly expressed in bone marrow of patients with AML compared to that of healthy controls $(\mathrm{HC})$. Moreover, the proportions of CD45 dim CD34 + CD38 - CD133 + cells were also examined in diverse hematology malignancies including $A M L, C M L, D L B C L, M M, M D S, H L, A L L$ and $C L L$. These cells were prominently detected in BMCs of AML and CML, but rarely in DLBCL, MM, MDS, ALL, CLL and HL. Additionally, the high levels of the CD45 dim CD34 + CD38 - CD133 + cells in AML patients were an independently significant poor risk factor for overall survival and event free survivals. Therefore, our results suggest that CD45 dim CD34 + CD38 - CD133 + cells in AML might have the potential of leukemia stem cells. In addition, this cell population might be a novel therapeutic target for AML.

\section{Background}

Acute myeloid leukemia (AML) is generally regarded as a stem cell disease, and it originates from a hierarchy of leukemic stem cell classes that differ in self-renewal capacity [1, 2]. Also, AML is a very heterogeneous disease, with abundant pathogenetic mutations defined, numerous mutations present, and significant differences in clinical outcome seen in individual patients [3]. Generally, it is rapidly lethal, and survival outcomes for adults with AML are very poor despite intensive chemotherapy and/or targeted therapies together with supportive care [4].

The leukemia stem cells (LSCs) in AML play important roles in development of leukemia, chemotherapeutic drug resistance, and disease relapse and progression [5]. Actually, the available evidence has recently been suggested that LSCs, which are capable of developing identical daughter cells as well as differentiated cells and maintaining $\operatorname{AML}[6,7]$. For examples, Rhenen et al showed that a high percentage of $\mathrm{CD} 4^{+} \mathrm{CD} 38^{-}$stem cells at diagnosis significantly correlated with a high minimal residual disease frequency and subsequently to relapse especially after the third course of chemotherapy in AML patients. Also, these cell populations directly correlated with poor survival $[2,5]$.

Searching for the LSCs population is one of the best ways to find treatment strategies, or improve treatment outcomes in AML and other malignant diseases [3]. Therefore, basic research on identification and targeting LSCs is actively under way. Many scientists have been interesting in this area and made efforts to find the appropriated biological markers of LSCs population in AML including CD $34^{+} \mathrm{CD} 38^{-}$cells

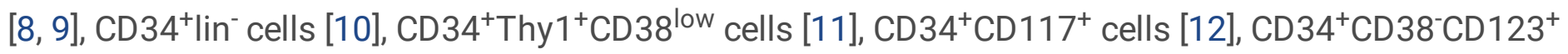
cells [13-15], CD 34 ${ }^{+} \mathrm{CD} 38^{-} \mathrm{CD} 123^{+} \mathrm{CD} 33^{+}$cells [16], CD 34 ${ }^{+} \mathrm{CD} 38^{-} \mathrm{C}$-type lectin-like molecule-1 $(\mathrm{CLL}-1)^{+}$

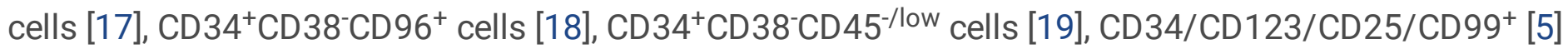
and so on. Moreover, the $\mathrm{CD} 34^{+} \mathrm{CD} 38^{-}$progenitor cells expressed variable amounts of the target receptor 
CD33, CD133 and c-kit (CD117) [20]. But all the researches have been still very confused. Therefore, we analyzed various existing information and created new combinations that could become LSCs.

Furthermore, it was developed using the basic platform of the CD $34^{+} \mathrm{CD} 38^{-}$markers, but applying more advanced antigens such as CD45 $\mathrm{dim}$ and CD133. In this study, we focused on measuring LSCs easily in the bone marrow cells from AML patients by developing a four-color flow cytometric analysis. Our studies suggest that $\mathrm{CD} 45^{\mathrm{dim}} \mathrm{CD} 34^{+} \mathrm{CD} 38^{-} \mathrm{CD} 133^{+}$cells have the potential of leukemic stem cells in AML patients.

\section{Methods}

\section{Reagents}

Mouse anti-human CD45-FITC (Clone 2D1, Cat No. 347463), Mouse Anti-human CD34-PE [Clone 8G12 (also known as HPCA2), Cat No. 348057], Mouse anti-human CD38-PE-Cy 5 (Clone HIT2, Cat No. 555461) and appropriated isotype control antibodies were purchased from BD Biosciences (San Diego, CA, USA). Mouse anti-human CD133-APC (Clone CD133, Cat No. 130-090-826) was obtained from Miltenyi Biotec (San Diego, CA, USA).

\section{Patient samples}

We analyzed bone marrow samples collected from 87 patients who were newly diagnosed with $A M L(n=$ $40)$, chronic myeloid leukemia ( $C M L, n=6)$, diffuse large B-cell lymphoma ( $D L B C L, n=19)$, multiple myeloma ( $M M, n=10)$, myelodysplastic syndrome (MDS, $n=5)$, Hodgkin lymphoma $(H L, n=4)$, acute lymphocytic leukemia (ALL, $n=3$ ) or chronic lymphocytic leukemia (CLL, $n=2)$ and from 27 healthy controls at Ulsan University Hospital, Ulsan, South Korea. Baseline clinical characteristics of 40 patients with AML were summarized in Supplementary Table 1. And the other patients' characteristics (expect AML) were summarized in Supplementary Table 2.

\section{Isolation of bone marrow cells}

The bone marrow cells (BMCs) were isolated by the density gradient method, as previously described [21]. In brief, BMCs were isolated via density gradient centrifugation at $400 \times g$ using Lymphoprep (Axis-Shield, Oslo, Norway; density, $1.077 \mathrm{~g} / \mathrm{mL}$ ). They were washed with phosphate-buffered saline (PBS).

\section{Flow cytometric phenotypic analysis}

The BMCs were collected and washed twice with FACS buffer (PBS containing $0.3 \%$ BSA and $0.1 \%$ NaN3). Cells were incubated with four antibodies against each cell surface antigens including CD 45, CD34, CD38, and CD133 on ice for 30 min. First of all, the live cells of BMCs were collected, and SSClow 
and $C D 45^{\text {dim }}$ cells were gated, as shown in Fig. 1A and 1B. The BMCs were incubated with three types of combinations of monoclonal antibodies (mAbs) on ice for $30 \mathrm{~min}$ such as isotype control 1 (Mouse antihuman CD45-FITC, Mouse IgG-PE, Mouse IgG-PE CY5, and Mouse IgG-APC), isotype control 2 (Mouse anti-human CD45-FITC, Mouse anti-human CD34-PE, Mouse anti-human CD38-PE CY5, and Mouse IgGAPC), and sample (Mouse anti-human CD45-FITC, Mouse anti-human CD34-PE, Mouse anti-human CD38PE CY5, and Mouse human CD133-APC), as shown in Fig. 1C and Fig. 1D. Cells were then washed twice with FACS buffer and analyzed using the FACSCalibur flow cytometer and CellQuest Pro software (BD Bioscience) as shown Fig. 1. Finally, CD $45^{\text {dim }}$ CD $34^{+} \mathrm{CD} 38^{-} \mathrm{CD} 133^{+}$cells, $\mathrm{CD} 133$ positive cells of the R1, R2, R3-gated cells were measured, and the results were expressed as percentage changes from the base conditions including isotype control 2.

\section{ELISA for cytokine measurements}

Cell-free plasmas from bone marrow samples from patients with AML were collected and frozen at $80^{\circ} \mathrm{C}$. Plasma levels of interleukin (IL) $-1 \beta, \mathrm{IL}-6, \mathrm{IL}-17$ and IL-23 were measured using ELISA kits according to manufacturer's introductions (R\&D Systems).

\section{Statistics}

The data presented here represent the means \pm standard error of mean (SEM) of at least three independent experiments. All values were evaluated by one-way analysis of variance followed by Turkey range tests implemented in GraphPad Prism 7.0. Differences were considered significant at $P<0.05$. For patients with $\mathrm{AML}$, continuous variables were compared using Student's t-test, whereas categorical variables were analyzed using the Pearson chi-square test or Fisher's exact test. Overall survival (OS) was calculated from the date of HCT to the date of death or last follow-up. Event-free survival (EFS) was defined from the date of HCT to the date of relapse or death from any cause. Survival probabilities were estimated by the Kaplan-Meier method. Univariate and multivariate analyses for OS, EFS, and relapse probability were performed using the log rank test and Cox proportional hazards model, respectively. The following variables were included for univariate analyses: $\mathrm{CD} 45^{\mathrm{dim}} \mathrm{CD} 34^{+} \mathrm{CD} 38^{-} \mathrm{CD} 133^{+}$cell proportion, age, white blood cell (WBC) count, platelet count, bone marrow blast percentage, cytogenetic risk groups, chemotherapeutic regimens and immunophenotypings including CD7, CD33, CD34, and HLA-DR. Variables with a $P$-value $<0.1$ in the univariate analyses were included in the multivariate analyses. The statistical analyses were performed with SPSS version 21.0 software (IBM Corp., Armonk, NY). For all analyses, the $P$-values were two-sided; a $P$-valueof $<0.05$ was considered statistically significant.

\section{Results}

The $C D 45^{\text {dim }} C D 34^{+} C D 38^{-} C D 133^{+}$cells are highly expressed in bone marrow of patients with acute myeloid leukemia, not healthy controls. 
The process of four-color flow cytometry experiments using monoclonal antibodies (mAbs) are shown in Fig. 1. As shown in Fig. $1 A$ and 1B, the live cells of BMCs were collected, and SSClow $/ C D 45^{\text {dim }}$ cells were obtained. The BMCs were stained with various combinations of mAbs on ice for 30 min such as isotype 1, isotype 2, and sample (Fig. 1C). Lastly, the CD133 positive cells of the R1, R2, R3-gated cells were measured by flow cytometer, and the results were expressed as percentage changes from the isotype 2 (Fig. 1D). A total of $40 \mathrm{AML}$ patients were examined for expression of the target antigens, $\mathrm{CD} 45^{\mathrm{dim}} \mathrm{CD} 34^{+} \mathrm{CD} 38^{-} \mathrm{CD} 133^{+}$cells on BMCs. These cells were highly expressed only in bone marrow samples of patients with AML, not in those of healthy controls (Fig. 2). These results indicated that CD $45^{\operatorname{dim}} \mathrm{CD} 34^{+} \mathrm{CD} 38^{-} \mathrm{CD} 133^{+}$cells in bone marrow have the potential of AML stem cells.

\section{Elevated IL-1 $\beta$, IL-6, IL-17 and IL-23 cytokine production of plasma in patients with AML}

We examined the IL $-1 \beta, I L-6, I L-17$ and IL-23 cytokine production in BM plasma samples, which they were matched BMCs in AML patients. Then plasma samples of the AML patients were shown higher levels of IL $-1 \beta, I L-6, I L-17$ and IL -23 cytokine production than those of healthy controls, as shown in Fig. 3.

\section{The CD45 $^{\text {dim }}$ CD34+CD38-CD133 ${ }^{+}$cells are prominently detected in BMCs of patients with $A M L$ and $\mathrm{CML}$}

As shown in Fig. 1, the $\mathrm{CD} 45^{\mathrm{dim}} \mathrm{CD} 34^{+} \mathrm{CD} 38^{-} \mathrm{CD} 133^{+}$cells were examined by four-color flow cytometry experiments in diverse hematology malignancy including AML $(n=40), C M L(n=6), \operatorname{DLBCL}(n=19), M M$ $(n=10), M D S,(n=5), H L(n=4), \operatorname{ALL}(n=3)$ and CLL $(n=2)$. These cells are significantly detected in BMCs of patients with AML and CML, not DLBCL, MM, MDS, ALL, CLL and HL. Once again, these results indicated that $\mathrm{CD} 45^{\mathrm{dim}} \mathrm{CD} 34^{+} \mathrm{CD} 38^{-} \mathrm{CD} 133^{+}$cells in bone marrow have the potential of acute myeloid leukemia stem cells. In addition, these cells might be feasible for AML stem cells marker.

\section{Clinical characteristics according to levels of the CD45 ${ }^{\text {dim }}$ CD $34^{+}$CD $38^{-}$CD $133^{+}$cells}

FLT3-ITD mutation in AML patients with higher CD45 ${ }^{\text {dim }}$ CD $34^{+}$CD 38 CD $133^{+}$cells $(\geq 10 \%)$ was significantly rarely found compared to those with lower CD $45^{\text {dim }}$ CD $34^{+}$CD $38^{-}$CD $133^{+}$cells $(<10 \%)(0 \%$ vs. $23.1 \%$, respectively, $P=0.031)$. In addition, higher $\operatorname{CD} 45^{\text {dim }} \operatorname{CD} 34^{+}$CD $38^{-} \mathrm{CD} 133^{+}$cells $(\geq 20 \%)$ were 
significantly associated with lower levels of $\mathrm{IL}-17$ expression, comparing to lower CD $45^{\mathrm{dim}} \mathrm{CD} 34^{+} \mathrm{CD} 38^{-}$ CD133 ${ }^{+}$cells $(<20 \%)(118.0$ vs. $35.0 \mathrm{pg} / \mathrm{ml}$, respectively, $P=0.028)$. However, there was no significant

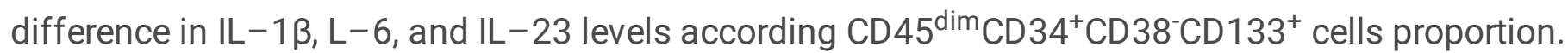

\section{High proportion of the CD45 ${ }^{\text {dim }}$ CD34 ${ }^{+}$CD38-CD133 ${ }^{+}$ cells predicts poor survival in AML patients}

When we divided AML patients into three groups according to $\mathrm{CD} 45^{\mathrm{dim}} \mathrm{CD} 34^{+} \mathrm{CD} 38^{-} \mathrm{CD} 133^{+}$cell proportions ( $<10 \%$ vs. $10-40 \%$ vs. $\geq 40 \%$ ), the 2 -year OS rate was $64.3 \%$ vs. $57.9 \%$ vs. $0 \%$, respectively ( $P$ $<0.001)$ and the 2 -year EFS was $62.3 \%$ vs. $37.2 \%$. vs. $0 \%(P=0.002)$ on univariate analysis (Supplementary Table 3). Among three groups (CD45 ${ }^{\mathrm{dim}} \mathrm{CD} 34^{+} \mathrm{CD} 38^{-} \mathrm{CD} 133^{+}$cell proportions $<10 \%, 10-$ $40 \%$ and $\geq 40 \%$ ), however, there were no significant differences in baseline clinical factors including age $(P=0.085)$, white blood cell count $(P=0.397)$, platelet count $(P=0.737)$, chemotherapy intensity $(P=$ 0.158). On univariate analyses for OS and EFS in patients with AML, older age (> 60 years) was significantly associated with worse OS compared to younger age $(32.8 \% \mathrm{vs.} 75 \%$ at 2 -year, respectively, $P$ $=0.041$ ) (Supplementary Table 3). In addition, patients with higher marrow blast $\%(\geq 60 \%)$ showed significantly lower OS rates than those with lower marrow blast \% (<60\%) $(36.7 \%$ vs. $66.7 \%, P=0.038)$ (Supplementary Table 3). Patients who were treated with intensive chemotherapy showed significantly better OS than those with hypomethylating agents ( $57.8 \%$ vs. $30.0 \%, P=0.012)$. When we consider together other clinical parameters in univariate and multivariate analysis, higher proportion of CD45 ${ }^{\text {dim }}$ CD $34^{+}$CD $38^{-} \mathrm{CD} 133^{+}$cells ( $\geq 40 \%$ ) was an independently significantly prognostic factor for OS (hazard ratio [HR], 6.810, $P=0.003)$ and EFS (HR, 9.028, $P=0.002)$ (Fig. 5. and Table 1).

\section{Discussion}

The conception that cancer stem cells including LSCs are responsible for initiation, drug resistance, and relapse of cancers has excited this area of research, and the importance of cancer stem cells has been demonstrated in a variety of tumors [6, 22-26]. Especially, LSCs have potential of unlimited self-renewal and are responsible for the maintenance of leukemia. Because selective eradication of LSCs could propose considerable therapeutic benefit, there has been interest in identifying the characterization of LSCs population that controls their development $[27,28]$. Therefore, the research related to prognostically relevant and potentially reliable molecular targets are needed.

AML is a hematopoietic disease that is characterized by clonal growth and the accumulation of myelopoietic progenitor cells [28]. It still remains a devastating and mostly incurable disease [4]. Moreover, therapy for AML involves intense cytotoxic treatment and yet approximately $70 \%$ of $A M L$ are refractory to initial therapy or eventually relapse [2]. This is at least partially driven by the chemo-resistant nature of the LSCs that maintain the disease. Therefore, novel anti-LSC therapies could decrease relapses and improve survival. 
The first LSC compartment that was described had the CD34 ${ }^{+} \mathrm{CD} 38^{-}$immunophenotype $[1,9]$. The CD34 ${ }^{+} \mathrm{CD} 38^{-}$compartment was shown to contain both $\mathrm{CD} 34^{+} \mathrm{CD} 38^{-} \mathrm{LSC}$ and normal hematopoietic stem cells (HSCs) [11]. Mawali et al. have proposed CD $34^{+} \mathrm{CD} 38^{-} \mathrm{CD} 123^{+}$cells as AML LSCs [15]. In the present study, the $\mathrm{CD} 45^{\mathrm{dim}} \mathrm{CD} 34^{+} \mathrm{CD} 38^{-} \mathrm{CD} 133^{+}$cells are examined by four-color flow cytometer experiments to define more specific and prognostically significant LSC population (Fig. 1).

The CD133 has been reported as a cancer stem cell marker in solid tumors [12, 29-31]. Several studies have shown that CD133positive cells have self-renewal properties, capacity for differentiation, high proliferation, and capacity for forming tumors in xenografts [30,31]. Although the precise function of CD133 remained unknown, it is associated with aggressive cancers and poor prognosis. CD133 has been known to be required for tumor growth and survival $[12,26,29]$. In hematologic malignancies including AML, however, clinical implications of CD133 expression have not been well known. Interestingly, $\mathrm{CD} 45^{\mathrm{dim}} \mathrm{CD} 34^{+} \mathrm{CD} 38^{-} \mathrm{CD} 133^{+}$cells are highly expressed in bone marrow of patients with $\mathrm{AML}$, not healthy controls (Fig. 2).

We also found raised IL-1 $1, \mathrm{IL}-6, \mathrm{IL}-17$ and IL-23 cytokine production in $\mathrm{BM}$ microenvironment of $\mathrm{AML}$ patients at diagnosis (Fig. 3). Carey et al. also reported that IL-1 and IL- $\beta$ might be associated with AML cell growth [32]. IL-3 has known to play a key role within the network of cytokines involved in the regulation of hematopoiesis and leukemic blast formation, although IL-3 has no prognostic significance [18]. Higher serum IL-17 levels have been known as an adverse prognostic factor in AML [22]. Otherwise, our results showed that $\mathrm{CD} 45^{\mathrm{dim}} \mathrm{CD} 34^{+} \mathrm{CD} 38^{-} \mathrm{CD} 133^{+} \mathrm{LSC}$ proportions in our study inversely correlated with IL-17 levels in BM microenvironments. There has been little data for cytokine IL-23 levels at AML diagnosis, although IL-23 have been reported to be associated with AML leukemogenesis and disease susceptibility in a previous study [33].

In addition, the $\mathrm{CD} 45^{\mathrm{dim}} \mathrm{CD} 34^{+} \mathrm{CD} 38^{-} \mathrm{CD} 133^{+}$cells were prominently detected in BMCs of patients with AML and CML, not in DLBCL, MM, MDS, ALL, CLL and HL (Fig. 4). Moreover, the prognostic significance of LSC has been reported in previous studies $[1,15]$. Tervinjin et al. showed higher CD34 ${ }^{+} \mathrm{CD} 45^{-} \mathrm{LAP}^{+}$cell proportions were related to poor survivals [1]. But, our study demonstrated that higher expression of the CD $45^{\text {dim }}$ CD $34^{+} \mathrm{CD} 38^{-} \mathrm{CD} 133^{+}$cells predict poor OS and EFS in AML (Fig. 5). These results also indicated that $\mathrm{CD} 45^{\mathrm{dim}} \mathrm{CD} 34^{+} \mathrm{CD} 38^{-} \mathrm{CD} 133^{+}$cells compartment in bone marrow could more discriminate LSC and normal hematopoietic stem cell and be a strong prognostic marker. Therefore, targeting $\mathrm{CD} 45^{\mathrm{dim}} \mathrm{CD} 34^{+} \mathrm{CD} 38^{-} \mathrm{CD} 133^{+}$cells could be a novel therapeutic direction in AML. Future studies will focus on the search about diminishment or elimination of the $\mathrm{CD} 45^{\mathrm{dim}} \mathrm{CD} 34^{+} \mathrm{CD} 38^{-} \mathrm{CD} 133^{+}$cells in patients with AML. Most importantly, high levels of the population are correlated with poor survival in AML patients. Therefore, our results indicate that $\mathrm{CD} 45^{\mathrm{dim}} \mathrm{CD} 34^{+} \mathrm{CD} 38^{-} \mathrm{CD} 133^{+}$cells function as $\mathrm{LSC}$ in AML.

\section{Conclusions}


We found that $C D 45^{\text {dim }} C D 34^{+} C D 38^{-} C D 133^{+}$cells have the potential of AML stem cells. Moreover, high levels of the $\mathrm{CD} 45^{\mathrm{dim}} \mathrm{CD} 34^{+} \mathrm{CD} 38^{-} \mathrm{CD} 133^{+}$cells are correlated with poor survival in AML patients. Therefore, our results indicate that $\mathrm{CD} 45^{\mathrm{dim}} \mathrm{CD} 34^{+} \mathrm{CD} 38^{-} \mathrm{CD} 133^{+}$cells function as LSCs in AML.

\section{Additional Files}

Additional file 1: Supplementary Table 1. Baseline characteristics of AML patients.

Additional file 2: Supplementary Table 2. Patient characteristics.

Additional file 3: Supplementary Table 3. Univariate analysis for AML patients.

\section{Abbreviations}

$\mathrm{BM}$, bone marrow; $\mathrm{BMCs}$, bone marrow cells; $\mathrm{HC}$, healthy controls; $\mathrm{AML}$, acute myeloid leukemia; $\mathrm{CML}$, chronic myeloid leukemia; DLBCL, Diffuse large B-cell lymphoma; MM, multiple myeloma; MDS, myelodysplastic syndrome; HL, Hodgkin lymphoma; $A L L$, acute lymphocytic leukemia; $C L L$, chronic lymphocytic leukemia.

\section{Declarations}

\section{Acknowledgments}

Not applicable.

\section{Authors' contributions}

SKH, EKN, YC, and JCJ designed the study. SKH, EKN, and YKJ performed the experiments. SKH, EKN, YKJ, JC, SK, and YJM analyzed and interpreted the experimental data. SKH, EKN, YKJ, JC, SK, and YJM provided the discussion and suggestions to the experiments. SKH, EKN, YC, and JCJ wrote the manuscript with input from all authors. All authors read and approved the final manuscript.

\section{Funding}

This study was supported by the Basic Science Research Program of the National Research Foundation of Korea (NRF), funded by the Ministry of Education, Science and Technology (NRF2017R1A1A3A04069314, NRF-2017R1C1B5015107); and the Biomedical Research Center, funded by the Ulsan University Hospital (UUHBRC-2016-001); and the Korea Health Technology R\&D Project through the Korea Health Industry Development Institute (KHIDI), funded by the Ministry of Health \& Welfare, Republic of Korea (HI17C0904). 


\section{Availability of data and materials}

All data generated or analyzed during this study are included in this published article and its additional files. Please contact the author Jae-Cheol Jo (jcjo97@hanmail.net) upon reasonable requests.

\section{Ethics approval and consent to participate}

All experiments were performed in accordance with the relevant guidelines and regulations. All patients provided written informed consent before the commencement of the study. The study protocol and patient informed consent form were approved by the Ulsan University Hospital Ethics Committee and Institutional Review Board (UUH-IRB-2016-07-026). The informed written consent was obtained from all included subjects before collecting the bone marrow samples.

\section{Consent for publication}

Not applicable.

\section{Competing interests}

The authors declare that no competing interests exist.

\section{Author details}

${ }^{1}$ Biomedical Research Center, Ulsan University Hospital, University of Ulsan College of Medicine, Ulsan 44033, Republic of Korea. ${ }^{2}$ Department of Hematology and Oncology, Ulsan University Hospital, University of Ulsan College of Medicine, Ulsan 44033, Republic of Korea.

\section{References}

1.Terwijn M, Zeijlemaker W, Kelder A, Rutten AP, Snel AN, Scholten WJ, Pabst T, Verhoef G, Lowenberg B, Zweegman S, et al: Leukemic stem cell frequency: a strong biomarker for clinical outcome in acute myeloid leukemia. PLoS One 2014, 9:e107587.

2.Laverdiere I, Boileau M, Neumann AL, Frison H, Mitchell A, Ng SWK, Wang JCY, Minden MD, Eppert K: Leukemic stem cell signatures identify novel therapeutics targeting acute myeloid leukemia. Blood Cancer J 2018, 8:52.

3.Chan WI, Huntly BJ: Leukemia stem cells in acute myeloid leukemia. Semin Oncol 2008, 35.326-335. 
4.Roboz GJ: Current treatment of acute myeloid leukemia. Curr Opin Oncol 2012, 24:711-719.

5.Angelini DF, Ottone T, Guerrera G, Lavorgna S, Cittadini M, Buccisano F, De Bardi M, Gargano F, Maurillo L, Divona M, et al: A Leukemia-Associated CD34/CD123/CD25/CD99+ Immunophenotype Identifies FLT3Mutated Clones in Acute Myeloid Leukemia. Clin Cancer Res 2015, 21:3977-3985.

6.Reya T, Morrison SJ, Clarke MF, Weissman IL: Stem cells, cancer, and cancer stem cells. Nature 2001, 414:105-111.

7.Tan BT, Park CY, Ailles LE, Weissman IL: The cancer stem cell hypothesis: a work in progress. Lab Invest 2006, 86:1203-1207.

8.Tolba FM, Foda ME, Kamal HM, Elshabrawy DA: Expression of CD133 in acute leukemia. Med Oncol $2013,30: 527$.

9.Bonnet D, Dick JE: Human acute myeloid leukemia is organized as a hierarchy that originates from a primitive hematopoietic cell. Nat Med 1997, 3:730-737.

10.Lapidot T, Sirard C, Vormoor J, Murdoch B, Hoang T, Caceres-Cortes J, Minden M, Paterson B, Caligiuri MA, Dick JE: A cell initiating human acute myeloid leukaemia after transplantation into SCID mice. Nature $1994,367: 645-648$.

11.Taussig DC, Miraki-Moud F, Anjos-Afonso F, Pearce DJ, Allen K, Ridler C, Lillington D, Oakervee H, Cavenagh J, Agrawal SG, et al: Anti-CD38 antibody-mediated clearance of human repopulating cells masks the heterogeneity of leukemia-initiating cells. Blood 2008, 112:568-575.

12.Park EK, Lee JC, Park JW, Bang SY, Yi SA, Kim BK, Park JH, Kwon SH, You JS, Nam SW, et al: Transcriptional repression of cancer stem cell marker CD133 by tumor suppressor p53. Cell Death Dis 2015, 6:e1964.

13.Wang W, Wang HY, Zhao HX, Cui ZG, Li GL: [Expression of CD133 in bone marrow cells of patients with leukemia and myelodysplastic syndrome]. Zhongguo Shi Yan Xue Ye Xue Za Zhi 2007, 15:470-473.

14.Reikvam H, Brenner AK, Hagen KM, Liseth K, Skrede S, Hatfield KJ, Bruserud O: The cytokine-mediated crosstalk between primary human acute myeloid cells and mesenchymal stem cells alters the local cytokine network and the global gene expression profile of the mesenchymal cells. Stem Cell Res 2015, 15:530-541.

15.Al-Mawali A, Gillis D, Lewis I: Immunoprofiling of leukemic stem cells CD34+/CD38-/CD123+ delineate FLT3/ITD-positive clones. J Hematol Oncol 2016, 9:61.

16.Hauswirth AW, Florian S, Printz D, Sotlar K, Krauth MT, Fritsch G, Schernthaner GH, Wacheck V, Selzer E, Sperr WR, Valent P: Expression of the target receptor CD33 in CD34+/CD38-/CD123+ AML stem cells. Eur J Clin Invest 2007, 37:73-82. 
17.Guenova M, Balatzenko G: CD133-2 (AC141) expression analysis in acute leukemia immunophenotyping in correlation to CD34 and P-glycoprotein. Hematology 2008, 13:137-141.

18.Binder S, Luciano M, Horejs-Hoeck J: The cytokine network in acute myeloid leukemia (AML): A focus on pro- and anti-inflammatory mediators. Cytokine Growth Factor Rev 2018, 43:8-15.

19.Toren A, Bielorai B, Jacob-Hirsch J, Fisher T, Kreiser D, Moran O, Zeligson S, Givol D, Yitzhaky A, Itskovitz-Eldor J, et al: CD133-positive hematopoietic stem cell "stemness" genes contain many genes mutated or abnormally expressed in leukemia. Stem Cells 2005, 23:1142-1153.

20.Mak AB, Nixon AM, Moffat J: The mixed lineage leukemia (MLL) fusion-associated gene AF4 promotes CD133 transcription. Cancer Res 2012, 72:1929-1934.

21. Heo SK, Noh EK, Yoon DJ, Jo JC, Park JH, Kim H: Dasatinib accelerates valproic acid-induced acute myeloid leukemia cell death by regulation of differentiation capacity. PLoS One 2014, 9:e98859.

22. Han Y, Ye A, Bi L, Wu J, Yu K, Zhang S: Th17 cells and interleukin-17 increase with poor prognosis in patients with acute myeloid leukemia. Cancer Sci 2014, 105:933-942.

23.Morrison SJ, Uchida N, Weissman IL: The biology of hematopoietic stem cells. Annu Rev Cell Dev Biol $1995,11.35-71$.

24.Weissman IL: Stem cells: units of development, units of regeneration, and units in evolution. Cell 2000, 100:157-168.

25.Al-Hajj M, Wicha MS, Benito-Hernandez A, Morrison SJ, Clarke MF: Prospective identification of tumorigenic breast cancer cells. Proc Natl Acad Sci U S A 2003, 100:3983-3988.

26.Lu L, Wu M, Sun L, Li W, Fu W, Zhang X, Liu T: Clinicopathological and prognostic significance of cancer stem cell markers CD44 and CD133 in patients with gastric cancer: A comprehensive metaanalysis with 4729 patients involved. Medicine (Baltimore) 2016, 95:e5163.

27.Wang Y, Krivtsov AV, Sinha AU, North TE, Goessling W, Feng Z, Zon LI, Armstrong SA: The Wnt/betacatenin pathway is required for the development of leukemia stem cells in AML. Science 2010, 327:16501653.

28.Sperr WR, Hauswirth AW, Florian S, Ohler L, Geissler K, Valent P: Human leukaemic stem cells: a novel target of therapy. Eur J Clin Invest 2004, 34 Suppl 2:31-40.

29.Joseph C, Arshad M, Kurozomi S, Althobiti M, Miligy IM, Al-Izzi S, Toss MS, Goh FQ, Johnston SJ, Martin SG, et al: Overexpression of the cancer stem cell marker CD133 confers a poor prognosis in invasive breast cancer. Breast Cancer Res Treat 2018. 
30.Singh SK, Hawkins C, Clarke ID, Squire JA, Bayani J, Hide T, Henkelman RM, Cusimano MD, Dirks PB: Identification of human brain tumour initiating cells. Nature 2004, 432:396-401.

31.Wu Y, Wu PY: CD133 as a marker for cancer stem cells: progresses and concerns. Stem Cells Dev 2009, 18:1127-1134.

32.Carey A, Edwards DKt, Eide CA, Newell L, Traer E, Medeiros BC, Pollyea DA, Deininger MW, Collins RH, Tyner JW, et al: Identification of Interleukin-1 by Functional Screening as a Key Mediator of Cellular Expansion and Disease Progression in Acute Myeloid Leukemia. Cell Rep 2017, 18.3204-3218.

33.Qian X, Cao S, Yang G, Pan Y, Yin C, Chen X, Zhu Y, Zhuang Y, Shen Y, Hu Z: Potentially functional polymorphism in IL-23 receptor and risk of acute myeloid leukemia in a Chinese population. PLoS One 2013, 8:e55473.

\section{Tables}

Table 1. Multivariate analysis for AML patients.

\section{HR for OS P-value HR for EFS $P$-value}

\begin{tabular}{|c|c|c|c|c|}
\hline \multicolumn{5}{|c|}{ 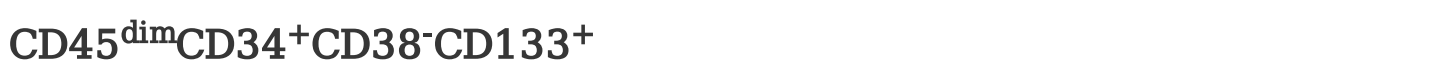 } \\
\hline$<10 \%$ & 1 & & 1 & \\
\hline $10-<40 \%$ & 2.460 & 0.110 & 2.731 & 0.089 \\
\hline$\geq 40 \%$ & 6.810 & 0.003 & 9.028 & 0.002 \\
\hline
\end{tabular}

Platelet count, $/ \mathrm{mm}^{3}$

$\begin{array}{lll}<40, \times 10^{3} & 3.196 & 0.076 \\ \geq 40, \times 10^{3} & 1 & \end{array}$

Chemotherapy

Intensive chemotherapy

1

1

Hypomethylating agent

3.845

0.014

4.829

0.010

\section{Figures}


Fig. 1. Heo et al.

\section{A Live cells-gated}

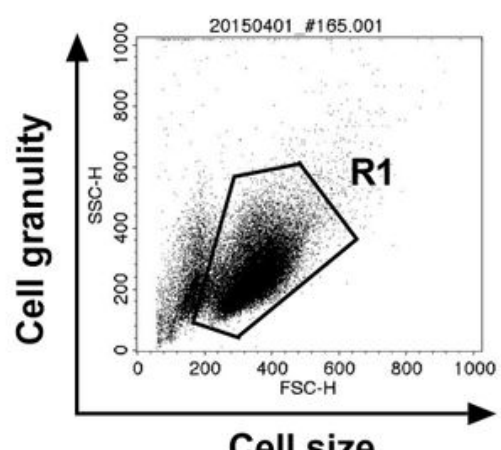

Cell size
B R1-gated

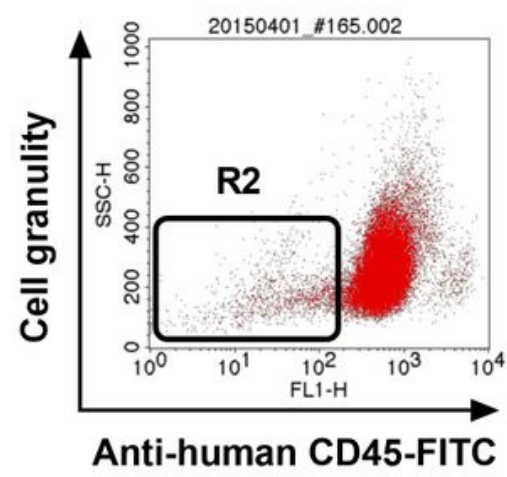

C R1, R2-gated
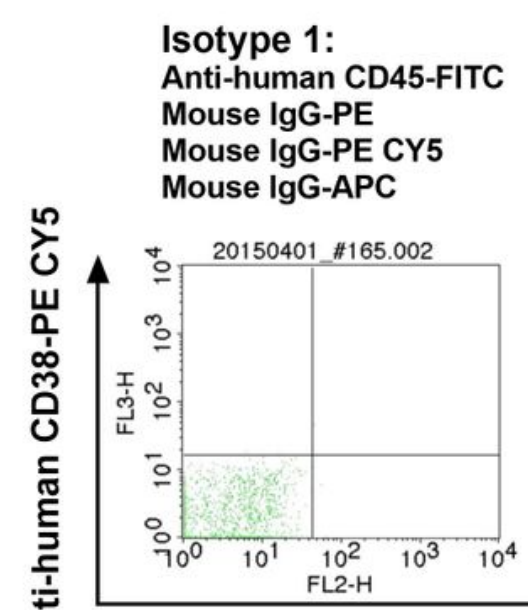

D R1, R2, R3-gated
Isotype 2:

Anti-human CD45-FITC

Anti-human CD34-PE

Anti-human CD38-PE CY5

Mouse IgG-APC

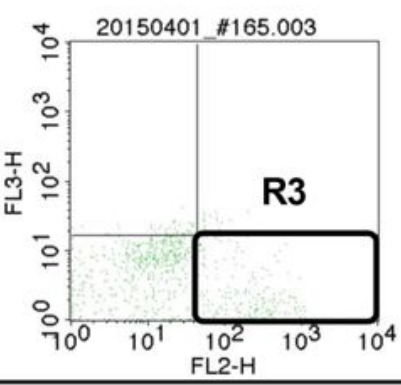

Sample:

Anti-human CD45-FITC

Anti-human CD34-PE

Anti-human CD38-PE CY5

Anti-human CD133-APC

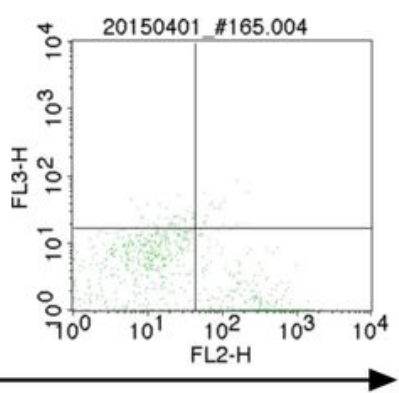

Anti-human CD34-PE

Overlay of isotype 2 and sample

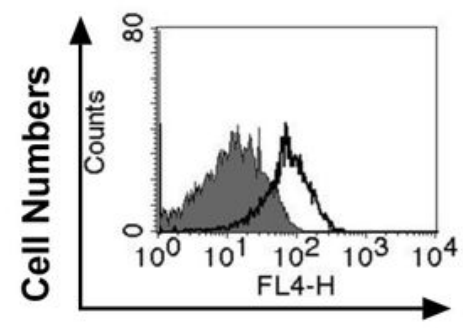

Anti-human CD133-APC

\section{Figure 1}

The process of four-color staining flow cytometry experiments using monoclonal antibodies. The BMCs were collected and washed twice with FACS buffer. Cells were incubated with four antibodies against each cell surface antigens including CD45, CD34, CD38, and CD133 on ice for $30 \mathrm{~min}$. (A, B) The live cells of BMCs were collected, and SSClow and CD45dim cells were gated. (C, D) The BMCs were incubated with three types of combinations of monoclonal antibodies (mAbs) on ice for 30 min such as isotype 
control 1 (Mouse anti-human CD45-FITC, Mouse IgG-PE, Mouse IgG-PE CY5, and Mouse IgG-APC), isotype control 2 (Mouse anti-human CD45-FITC, Mouse anti-human CD34-PE, Mouse anti-human CD38-PE CY5, and Mouse IgG-APC), and sample (Mouse anti-human CD45-FITC, Mouse anti-human CD34-PE, Mouse anti-human CD38-PE CY5, and Mouse human CD133-APC). Cells were then washed twice with FACS buffer and analyzed using the FACSCalibur flow cytometer and CellQuest Pro software (BD Bioscience). Finally, CD45dimCD34+CD38-CD133+ cells, CD133 positive cells of the R1, R2, R3-gated cells were measured, and the results were expressed as percentage changes from the base conditions including isotype control 2 . The filled histogram represents the isotype control 2 , and the open histogram represents CD45dimCD34+CD38-CD133+ cells. 


\section{Fig. 2. Heo et al}

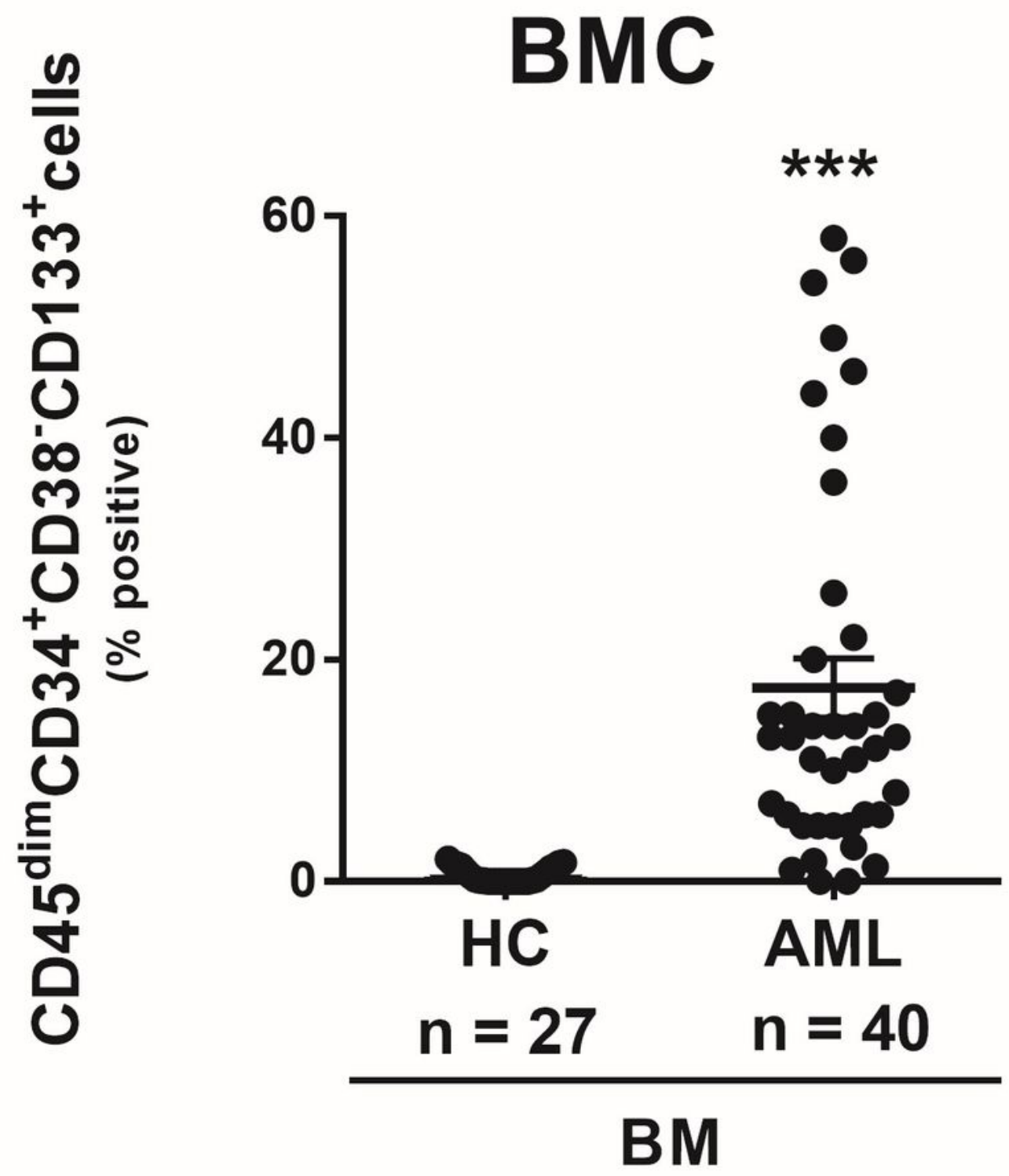

Figure 2

The CD45dimCD34+CD38-CD133+ cells are highly expressed in bone marrow of patients with AML, not healthy controls. Bone marrow cells from healthy controls and AML patients were examined for expression of the target antigens, CD45dimCD34+CD38-CD133+ cells. Data represent mean \pm SEM representing three independent experiments from different AML patients. Significantly different from the control (*); ***, $P<0.001$. HC, healthy controls; AML, Acute myeloid leukemia patients. 
Fig. 3. Heo et al
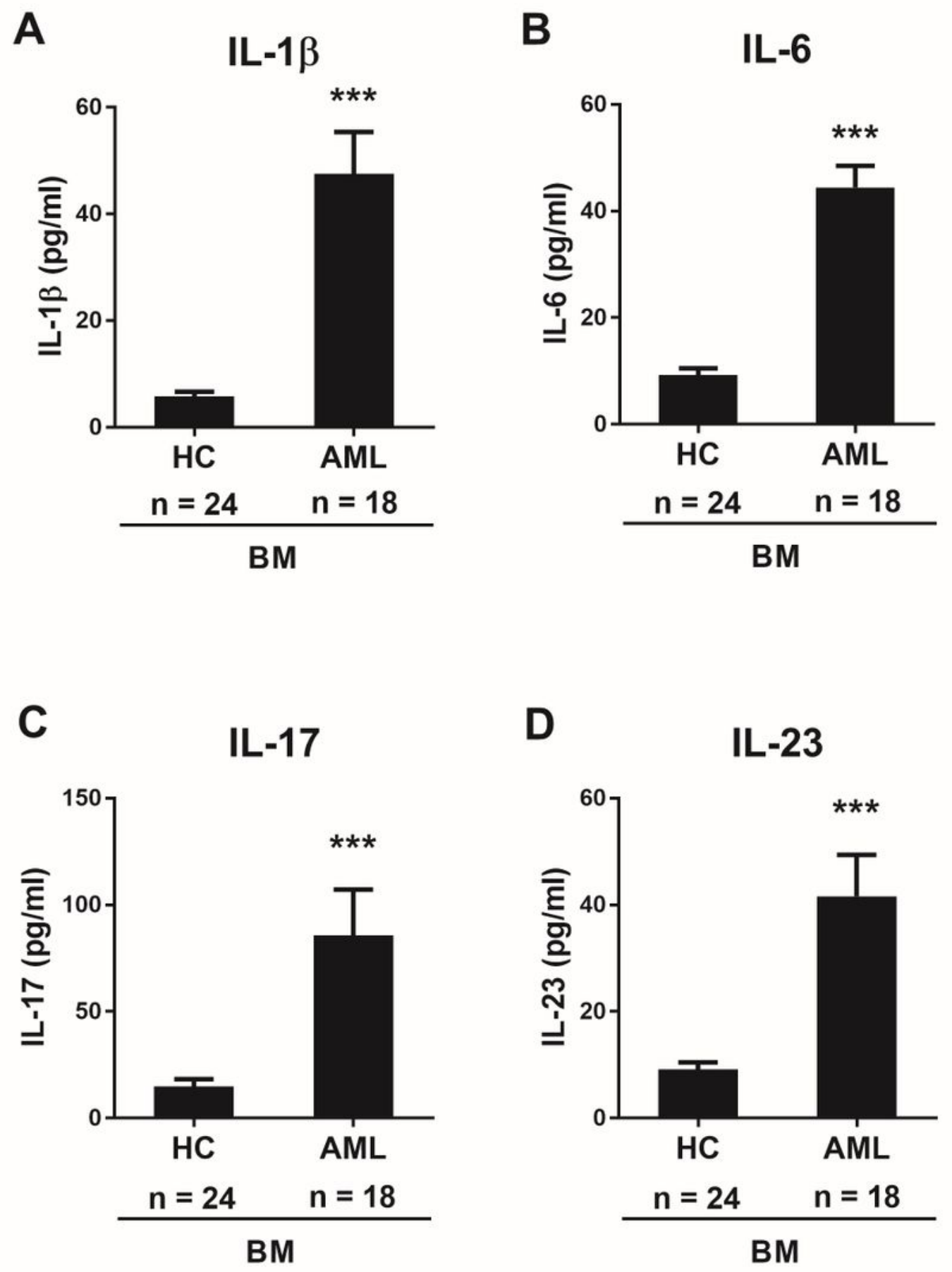

Figure 3

Measure the production of cytokines in plasma from healthy controls and AML patients. Cell-free plasmas from bone marrow samples from patients with $A M L$ were collected and frozen at $-80^{\circ} \mathrm{C}$. Plasma levels of interleukin (IL)-1 $\beta$, IL-6, IL-17 and IL-23 were measured using ELISA kits according to manufacturer's introductions (R\&D Systems). Data represent mean \pm SEM representing three independent 
experiments from different AML patients. Significantly different from the control (*); ${ }^{\star \star \star}, P<0.001$. HC, healthy controls; AML, Acute myeloid leukemia patients; BM, Bone marrow.

\section{Fig. 4. Heo et al}

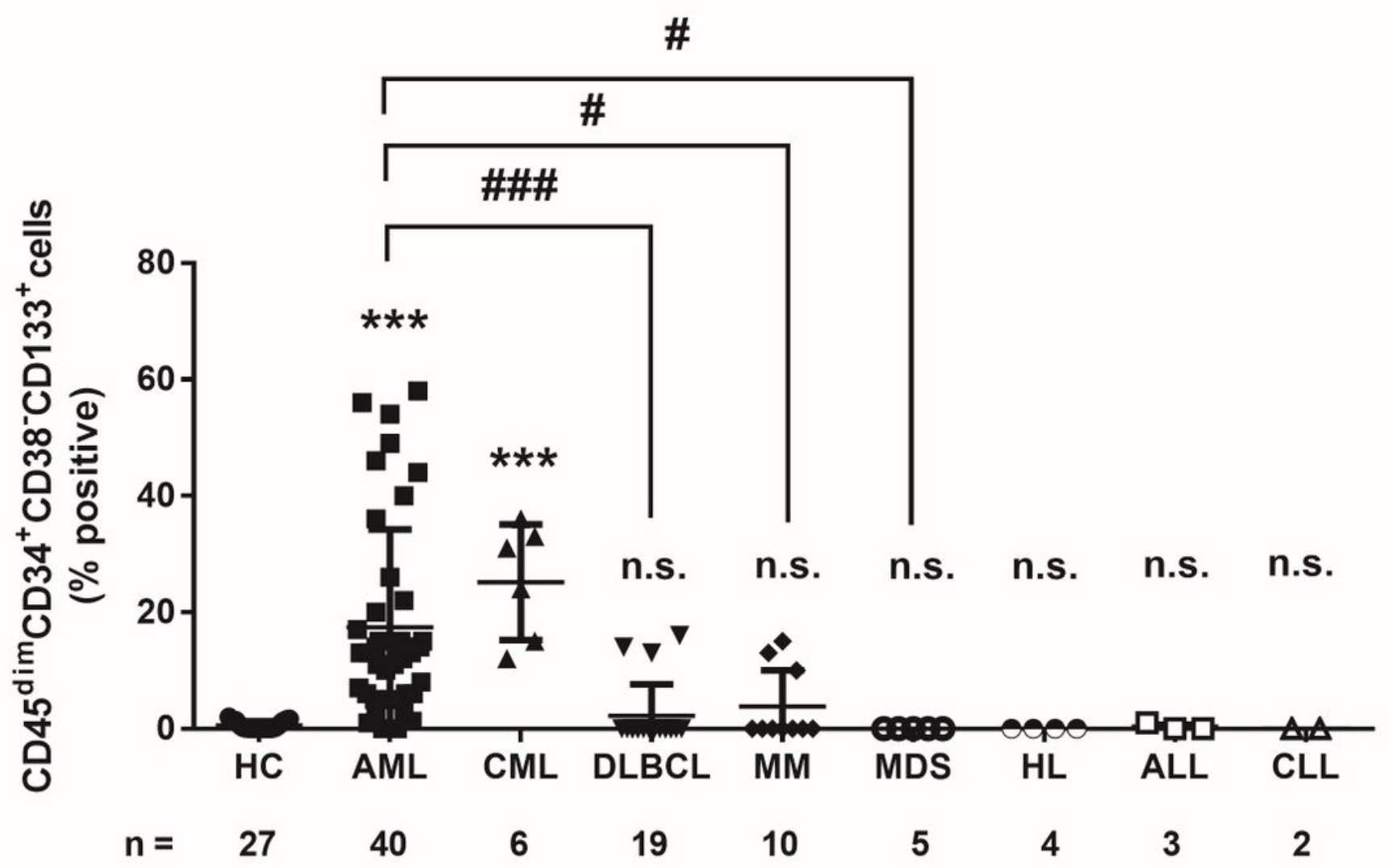

Figure 4

. The CD45dimCD34+CD38-CD133+ cells are prominently detected in BMCs of patients with AML and CML. As shown in Fig. 1, the CD45dimCD34+CD38-CD133+ cells were examined by four-color flow cytometry experiments in diverse hematology malignancy including AML $(n=40), C M L(n=6), D L B C L(n$ $=19), M M(n=10), M D S,(n=5), H L(n=4), \operatorname{ALL}(n=3)$ and CLL $(n=2)$. Data represent mean \pm SEM representing three independent experiments from different $A M L$ patients. Significantly different from the

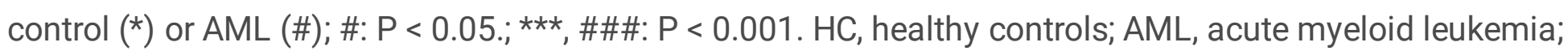
$\mathrm{CML}$, chronic myeloid leukemia; DLBCL, Diffuse large B-cell lymphoma; MM, multiple myeloma; MDS, myelodysplastic syndrome; HL, Hodgkin lymphoma; ALL, acute lymphocytic leukemia; CLL, chronic lymphocytic leukemia. 
Fig. 5. Heo et al

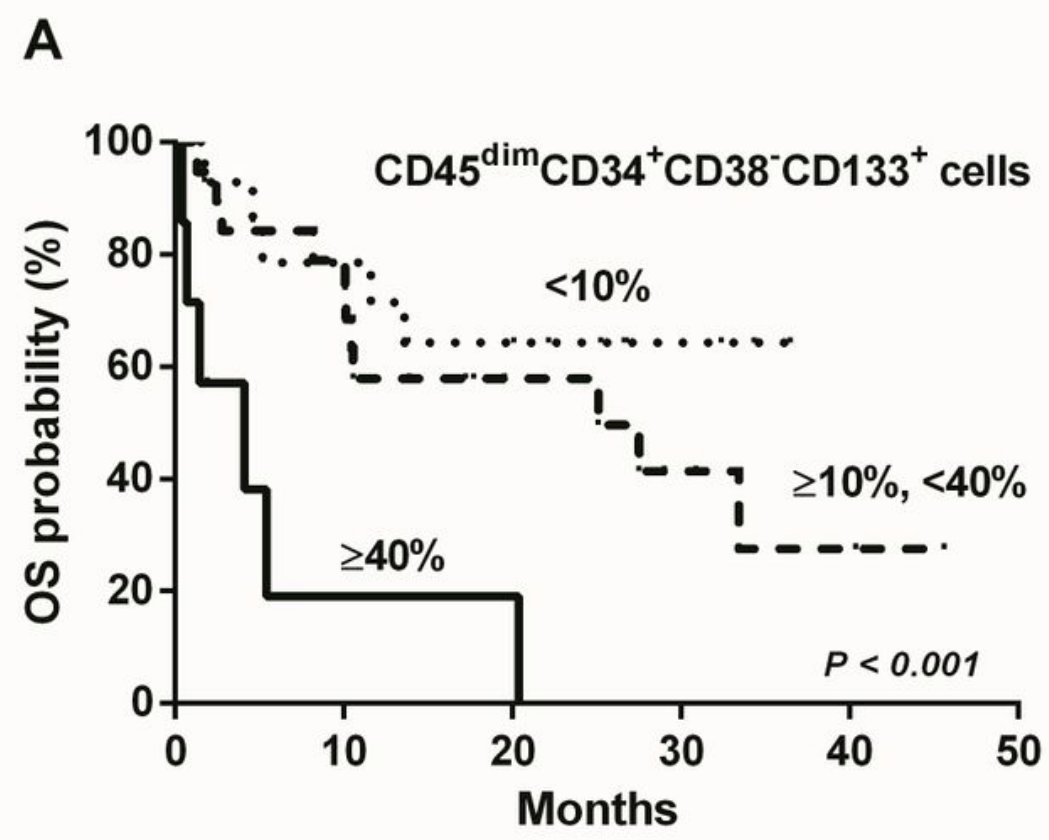

B

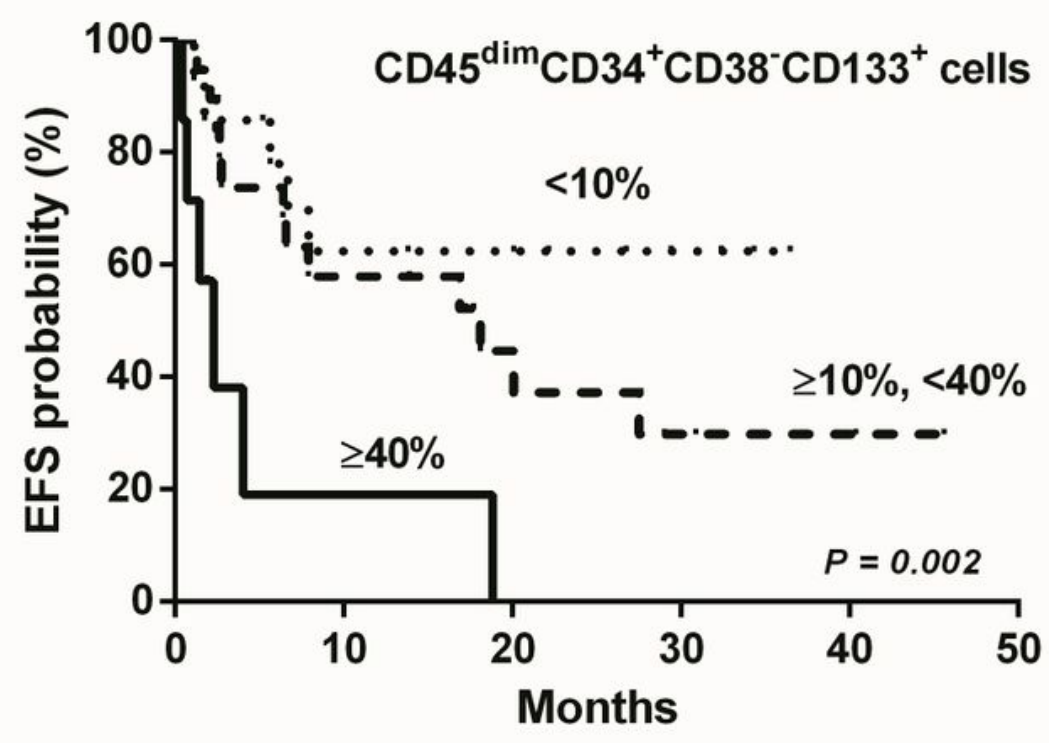

Figure 5

High proportion of the CD45dimCD34+CD38-CD133+ cells predicts poor survival in AML patients. (A) Higher CD45dimCD34+CD38-CD133+ cell proportion was significantly associated with worse OS $(P<$ 0.001). (B) Poorer EFS was significantly associated with higher CD45dimCD34+CD38-CD133+ cell proportion $(P=0.002)$. 


\section{Supplementary Files}

This is a list of supplementary files associated with this preprint. Click to download.

- LSCSupplementaryTablesHeoetal0717.docx 